\title{
LA XIII ASAMBLEA DE LA SOCIEDAD OFTALMOLÓGICA HISPANO AMERICANA (1923) Y «EL USO DE LOS ANTOJOS» (1623)
}

\author{
LÓPEZ DE LETONA C ${ }^{1}$
}

La celebración de la XIII Asamblea de la Sociedad Oftalmológica Hispano Americana en Sevilla los días 16 al 19 de septiembre de 1923 tuvo especiales características, la primera que tres días antes se acababa de producir el golpe de Estado del general Primo de Rivera y la segunda que ese año no correspondía celebrar reunión dado que al principio éstas tenían carácter bianual y se acaba de celebrar una en Bilbao el año anterior.

Pero se daba la circunstancia de cumplirse el trescientos aniversario de la aparición en la misma Sevilla de la conocida obra Uso de los antojos de la que era autor Benito Daza de Valdés, por ello se solicitó en Bilbao que tuviese lugar otra asamblea al año siguiente. Aprovechándose además para reeditar la obra.

Los asuntos oftalmológicos tratados en Sevilla se ciñeron en torno al tracoma limitándose a una serie de comunicaciones presentadas por los escasos asistentes a la reunión, con excepción hecha del omnipresente Márquez faltó la presencia de algunas figuras importantes de la especialidad.

Citaremos no obstante al valenciano Eduardo Wieden que se refirió al tracoma y su profilaxis o al Dr. Gradaille que disertó sobre la frecuencia del tracoma en La Coruña, igualmente debemos citar a los Dres. José Cordero Soroa y a Mérida Nicolich.

Las dos únicas comunicaciones distintas al «tema oficial» fueron las de Ramón Castroviejo: Contribución al tratamiento de los angiomas, y Ribas Valero que se refirió a los tumores malignos epibulbares.

Antes de referirnos al verdadero motivo de la reunión, es decir la celebración del trescientos aniversario de Uso de los antojos señalaremos que se presentó una pequeña exposición bibliográfica histórico oftalmológica de textos de la especialidad. El más antiguo databa de 1743 , se trataba en realidad de obras pertenecientes a bibliotecas privadas de ilustres oftalmólogos, entre ellos Márquez y Menacho.

En el libro de actas que hemos consultado aparecen por vez primera una serie de conclusiones de la reunión, pedían varias reformas, entre ellas la convocatoria de todas las plazas de catedráticos que estaban vacantes y la promulgación de una ley de sanidad, acaso todo se hiciese al amparo de la nueva situación política, también diversas medidas referentes al tracoma, esta afección en sí misma no debía ser motivo de inutilidad para el servicio militar y que la propia sociedad oftalmológica debía constituirse como un centro consultivo nacional del tracoma al que acudirían todos los afectados.

En cuanto a la celebración del trescientos aniversario de la edición de la obra citada hay que señalar que todo se debía a iniciativa de Zbikosky que poseía un ejemplar de la primera edición y se lo había ofrecido a Manuel Márquez para realizar un facsímil que apareció en el citado 1923.

Con ese motivo la reedición contó con un muy completo estudio de Márquez quien a lo largo de cuarenta páginas analiza la obra minuciosamente refiriendo muchos datos sobre la invención de los anteojos, su posterior evolución, las diversas clases de vidrios ...

Debemos indicar además que después del facsímil de 1923, cincuenta y un años más tarde se volvió a realizar otro incluyéndolo en una colección que patrocinaba la Real Academia de Medicina de Madrid y que llevaba por título «Biblioteca clásica de la medicina española», en ella se reproducía el texto completo de la obra que era éste: Uso de los antojos para todo género de vistas en que se enseña a conocer los grados que a cada uno le faltan de su vista y los que tienen cualquier antojo y así mis-

\footnotetext{
1 IOBA. Valladolid. España.

E-mail: berta@ioba.med.uva.es
} 
mo a que tiempo se han de usar y como se pedirán en ausencia, con otros avisos importantes a la utilidad y conservación de la vista.

Hay que señalar antes que nada que Benito Daza de Valdés es un personaje rodeado de cierto misterio, del que se poseen muy pocas noticias, de comienzo no tenía nada que ver con la medicina ni siquiera con la óptica ya que se trataba de un notario de la Inquisición, probablemente sacerdote.

Se ha indicado con frecuencia que acaso por su trato frecuente con los Dominicos, que eran los inquisidores habituales, pudo llegar a tener conocimientos sobre la materia, ya que es frecuente en la iconografía al uso, ver a los frailes de esta orden luciendo en algunas ocasiones los referidos anteojos.

Curiosamente la obra, que viene precedida de todas las licencias necesarias en aquel tiempo para su impresión y distribución viene precedida de numerosos versos, dedicados a la Virgen de la Fuensanta patrona de Córdoba, lugar de donde al parecer era natural Daza de Valdés.
Sabemos que se han realizado numerosos estudios y análisis a cerca de esta obra, probablemente uno de los texto históricos oftalmológicos más importantes en la historia de la especialidad, pero no podemos por menos de indicar algunas particularidades del mismo.

La obra se estructura en tres partes (libros) las dos primeras subdivididas en capítulos. El primer libro se subtitula: «De la naturaleza y propiedades de los ojos» y el segundo «Del remedio de la vista por medio de los antojos».

El tercer libro consta de una serie de diálogos, exactamente cuatro entre varios personajes que padecen diversas afecciones oculares. En todos ellos se propugna el uso de los anteojos (Antojos) prefiriendo los de cristal a los de vidrio.

Por otra parte el texto se ilustra con varios y curiosos dibujos, entre los que figuran algunos destinados a medir las dioptrías en cada defecto refractivo. Otro de ellos constituye a día de hoy el logotipo de la Sociedad Española de Oftalmología. 